European journal of American studies

Summer 2015, including Special Issue: (Re)visioning America in the Graphic Novel

\title{
Young Adult Pop Fiction: Empathy and the Twilight Series
}

\section{Alicia Otano Unzue}

\section{(2) OpenEdition \\ Journals}

Electronic version

URL: https://journals.openedition.org/ejas/11141

DOI: $10.4000 /$ ejas. 11141

ISSN: 1991-9336

Publisher

European Association for American Studies

Electronic reference

Alicia Otano Unzue, "Young Adult Pop Fiction: Empathy and the Twilight Series", European journal of American studies [Online], 10-2 | 2015, document 22, Online since 14 August 2015, connection on 08 July 2021. URL: http://journals.openedition.org/ejas/11141 ; DOI: https://doi.org/10.4000/ejas. 11141

This text was automatically generated on 8 July 2021 .

Creative Commons License 


\section{Young Adult Pop Fiction: Empathy and the Twilight Series}

Alicia Otano Unzue

\section{Introduction}

1 Stephenie Meyer's Twilight series, far from outstanding in literary quality, has decisively marked the adolescent popular fiction canon. Enter the word "Twilight" into any search engine and a proliferation of web sites on all the paraphernalia related to the saga, including the corresponding book reviews, appear. A longer look at the reams of Twilight-related information leaves one with an impression that the subject matter is controversial: hailed by America's religious right for its affirmation of traditional family values, this vampire series has been simultaneously attacked by a more liberal sector for the exaltation of traditional male/female stereotypes. The first book, Twilight, published in 2005, reached the fifth place on The New York Times bestseller list and was awarded the ALA Top Ten Books for Young Adults along with Amazon. Com.'s "Best Book of the Decade So Far" all in that same year. Its highly anticipated sequel, New Moon, released in September of 2006, spent twenty-five weeks in first place of The New York Times bestseller list (Stephenie Meyer. Official Website). The other two books that followed: Eclipse and Breaking Dawn matched their precursors' success rates. As the first young adult book series in America to achieve a Harry Potter type of phenomenal success, an analysis of its narrative landscape becomes essential to understanding its 
emotional appeal throughout the United States and much of the modern world.

2 What warrants an in-depth study of this paranormal, traditional romance, however, is the role that the adolescent or young adult reader played in converting it into a cross-cultural phenomenon. An analysis of the role of empathy in Meyer' narrative provides a better understanding of how this author has been able to make an old story look new: Twilight readers have bonded with Meyer's characters so well that they have been swept up by the series, going on to buy the next book. What fuels this empathetic connection between her main characters and the reader, and what results from this narrative encounter? Such questions become inevitable in the face of the intense teen reader involvement, which confirms what Susanne Keen observes in Empathy and the Novel about "empathyinducing blockbusters" and their role as "powerful tools" in terms of book sales (83).

s Meyer's work can be better appreciated for what it is when approached through the prism of recent research on the role of the human emotions at work when readers embark on a journey through narrative of the type that concerns us here, popular fiction. It is, indeed, in this type of fiction, offering an ample range of social settings and corresponding characters, that we can see other perspectives and improve our understanding of these. Nonetheless, literary studies and philosophy (including literary criticism and narrative ethics) seem to have a "largely unexamined, vexed-often openly contemptuousrelationship" with this specific kind of fiction as Keen affirms in Empathy and the Novel(83),yet the genre has become a sociological phenomenon in its own right and deserves serious analysis because of its large-scale consumption. The fact that best-seller lists serve to gauge authors' success and not the actual quality of their literary works cannot be denied. Making it on the New York Times' best-seller list has become a passport to fame and success.

4 The analysis undertaken here on the role of the emotion of empathy in the Twilight series attempts to contextualize this book phenomenon within the recent work by two specialists in the area of emotions, and specifically, empathy in literature: Susanne Keen and Patrick Hogan. Concomitantly, it is grounded on Martha Nussbaum's perspective on the role of narrative in eliciting empathy in the reader. In terms of emotions theory, my analysis works 
on the premise that pop fiction best-sellers of this kind cannot be ignored because they appeal to a vast area of human emotional life. Meyer has "tapped into the moment" in terms of what $21^{\text {st }}$-century adolescents and young adults want to read about and seem to connect with. As these works are converted into money-making series, they trigger a readership which is worth examining in terms of what both the author writing a sequel and the reader who buys it in installments pursue.

\section{The Role of Reader Empathy in the Romance Narrative Paradigm}

5 Unfortunately, the reader of popular fiction is usually ignored because of the mediocre quality of the work he/she consumes, as opposed to the minority high-brow, more intellectual reader who has always played a determining role in establishing the literary canon. I argue that the pop fiction consumer of series like Twilight deserves a more serious consideration: they are the ones that contribute to creating a phenomenon. Keen claims that, for diverse reasons, the average reader who populates the book clubs and buys most of the fiction sold in the United States and Great Britain seeks empathetic reading experiences. Novels engaging reader empathy always do better in the marketplace (possibly because of word-of-mouth recommendations). This sheds light on the Twilight saga's best-seller status: narrative empathy may be less influential as an effect of reading and more important as a soughtafter experience, and, in Keen's words, "tantamount to a precondition for success with a large segment of the bookbuying and novel reading public" (105). Needless to say, these communicative products, packaged in book format, both depict and induce emotional response cross-culturally.

6 The formal definition of what is considered to be an emotion per se becomes essential to understanding what is going on behind the scenes in Meyer's vampire world of Forks. Keith Oatley and Jennifer M. Jenkins offer a clear explanation of this concept through the use of stages in human interaction indicating what occurs when human beings actually experience one. In essence, an event, usually unexpected, is perceived by a human as a way to change the status of a valued goal. Beliefs are thus challenged, causing bodily changes and expressions, and ultimately, plans are formed about what to do about the 
event to reinstate or modify the goal (98). All of this clearly defines what occurs in the universal romance paradigm to which Twilight belongs and whose internal dynamics thrive, precisely, from empathy. This study is concerned with the nature of this emotional appeal which could serve to explain why a story about vampires, shape-shifters and human love (nothing new for a public familiar with the American television series Buffy the Vampire Slayer and the Vampire Diaries) has had a strong enough impact to convert it into a global success. Fundamentally, Twilight, in its serialized version, is about the emotions of relating, and its young adult protagonists tell us stories of love and anger-those same emotions associated with relationships. Keith Oatley observes in Such Stuff as Dreams: "there's always more to understand about these issues. They are critical to what is most important to us, but their implications are often a bit beyond our mental reach and this is where simulations (dreams) of the kind that fiction offers can come in" (169-170).

7 In terms of cognitive psychology, simply speaking, empathy is understood to be the ability to comprehend another individual's perspective and to have a resulting emotional reaction. It involves understanding others' points of view and recognizing one's own intuitive and emotional reaction to these. Keith Oatley believes that readers' personal experiences of patterns of emotional response provoke sympathy for characters, especially as readers identify with characters' goals and plans. Empathy, thus, combines affective and cognitive processes. The first is determined by emotional sympathy and the latter by the possibility of performing a change of perspective to the position of another person. ${ }^{i}$ As a writer, Meyer actively tunes into these two processes using Bella's filtering consciousness as a narrative tool offering the reader abundant description, monologues, and dialogues that are engrossing enough to trigger empathetic response.

${ }_{8}$ It has long been believed that the quality of a novel somehow inheres in the empathy it evokes.i As stated previously, Nussbaum bases her main argument on the beneficial aspects of reader empathy on Marcel Proust's analysis of the power of empathy in successful fiction. This widespread belief held by the international literary community on all levels, from writer to critic, represents a continuation of an established critical standard by which successful fictional characters are those who command 
readers' sympathies. Nonetheless, $21^{\text {st-century narrative }}$ style has replaced the traditional sympathetic feeling "for" with a contemporary empathetic feeling "with." At its best, the initial identification process (feeling with) evolves into an empathetic relationship ultimately causing a phenomenon like Twilight to occur when it is drawn out into a serialized version. For instance, the young adult reader identifies with Bella to the extent that he/she feels her pain, confusion and affection-and wants to buy the next book in the series.

9 Indeed, as the main character and the principal narrator in the Twilight series, Bella mediates the reading public's access to the unusual worlds she lives in. She is a $21^{\text {st }}$ century heroine moving in and out of a world of supernatural misfits of which she feels a part. For a young reader, the theme of otherness is fascinating when one is in the process of learning how to fit or not fit in with different groups. In fact, as Diane Sheets observes, part of Edward's, the Cullens', and the Quileute shape-shifters' attraction is "their status as outsiders and moral guardians" (112). Edward and his siblings are described by Bella as exceedingly attractive, both physically and personally. She is mesmerized by them, even though initially she feels very uncomfortable around them. Jacob and his pack members, when they do not shift their shapes, also fascinate her: this is nothing new to young adult fiction which thrives on the familiar scenario featuring a protagonist who embodies a potentially dangerous, but always seductive presence.

10 This vampire series' plot, however, confirms the heroine's instinctive belief that keeping company with sinister beings is good. From the start, her bonding with the supernatural misfits is explored by Meyer who as a writer is fascinated by the complex emotions derived from adolescent relationships, filling page after page of her four volumes with depictions of complex bonding processes. She presents cooperation as crucial in fulfilling her characters' happiness: the role that love and happiness play in the lives of Bella, Edward, and Jacob is intricately tied to commitment. The reader lives through the corresponding anguish evoked when the characters' actions are misinterpreted by those they love: Edward leaves Bella to save her life, or Jacob stops seeing her to obey his pack. The heroine's pain is witnessed by the reader in her monologues: her feelings and fears that any human being can relate to and the reader is thus drawn into the story. 
Doubtlessly, this story-sharing process involves the teen pursuit of romantic and familial happiness, but the innovative twist (and the likely reason for its cross-cultural success) is the insertion of supernatural misfits. Vulnerable vampires and werewolves, in terms of human feelings, go beyond the average marginalized types portrayed in fiction, which adds a new dimension to an old argument.

11 Vulnerability is something the reading public can connect with since happiness and sadness, with respect to others, involve the very basic notion of help, in all its dimensions as opposed to antagonism. As an emotion, when achieved by the Twilight protagonists, happiness is always borne out of a cooperation that must be freed of antagonism. In fact, in the series, happiness is derived from abstaining from any disruptive, violent behavior (antagonism), as Sarah Schwartzman observes in the chapter "Is Twilight Mormon?" from The TwilightMystique, and by exerting "free agency and sacrifice" (124). Love and happiness are, in fact, the bright threads in the gloomy tapestry of rain-drenched Forks. Meyer alludes to this subliminal message on aspiring to happiness in the interview by Lev Grossman for Time magazine: "I really think that is the underlying metaphor of my vampires; it doesn't matter where you're stuck in life or what you think you have to do: you can always choose something else. There's always a different path" ("Stephanie Meyer: A New J.K. Rowling?").

${ }_{12}$ Carlisle is an embodiment of this belief and therefore transmits the message eloquently in the scene in New Moon wherein he cleans Bella's wound after she has accidentally cut herself at the Cullens' house, causing the weaker Cullen sibling, Jasper, to attack her. Bella admires this tireless surgeon who never loses self-control at the sight of blood and comments: "You try very hard to make up for something that was never your fault; what I mean is, it's not like you asked for this. You didn't choose this kind of life, and yet you have to work so hard to be good." To which he answers: "I don't know that I'm making up for anything; like everything else in life, I just had to decide what to do with what I was given (35). As the Cullens' parent figure, he appears to be an ideal role model not only as a good vampire but as a good person: he has achieved the selfcontrol and attitude towards life which in the eyes of Bella seems to have brought him a state of happiness that they are all still in the process of acquiring. 


\section{Changing Interpersonal Geographies and Reader Empathy}

${ }_{13}$ Emotional survival skills, or perhaps emotional competence of the kind Carlisle stands for, is something all of Meyer's adolescent characters slowly acquire in her vampire series. In Breaking Dawn, the teenagers, who shape-shift into a wolf pack because of the heavy concentration of vampires in Forks, must learn to control their instinctive hate for these ancestral enemies. Obliged to join the Cullen coven to fight off a greater enemy, the evil Volturi coven, their fear and distrust still continues. It causes friction between pack members and, in a monologue in chapter 11, Jacob describes how he struggles with their instinctively violent reactions: "I won't just watch while the pack kills innocent-it was hard to apply that word to vampires but it was true-people. The pack is better than that" 211 ; original italics). Once again, the message here is that antagonism must be avoided at all cost, and his view of the Cullens as people is what alleviates an otherwise tense situation.

${ }_{14}$ Constant emotional turmoil permeates the pages of Twilight, which is not surprising in the light of the complicated socialization process between humans, vampires and shape-shifting werewolves. These relationships are continuously tested by the struggle over status and power which become crucial in the dynamics of the main characters' relationships. These two concepts are translated, when discussing fiction, into the well-known terms of affection and aggression. Keith Oatley and Jennifer Jenkins describe the emotional interplay at work in real life human social dynamics by using the two coordinates of affection and aggression as if they were geographical coordinates on an emotional map going North-South or East-West (225). Such coordinates allow us to locate ourselves at any moment in our own interpersonal geography, which is basically a metaphor for social interaction with those around us. In the universal romance paradigm, help and antagonism amongst the characters are what makes for situations that are recognizable to a reader who could likely live out (or may have already lived out) similar situations with their peers in real life.

${ }_{15}$ As with all emotions, affection and aggression (antagonism) occur when one's position in one's 
interpersonal geography, or one's social interaction, changes. The emotions felt when affection, love, and support (help) are given or received amount to happiness. When one is persecuted and destroyed for being what one is, as is the case with Meyer's supernatural misfits, hate or distrust inevitably result. Asserting power occurs via the emotions of anger and contempt, and when a person feels threatened, fear and anxiety occur. Such emotions are continuously encountered by the reader: the emotional upheavals experienced as a result of circumstances thrust upon the protagonists, are in fact of the kind most teenagers and young adults go through every day: the only variant is the supernatural context. In Bella's case, moving to small, rain-drenched Forks to live with her Dad proves to be a tumultuous change. Edward, in turn, represses his feelings for Bella, puts her life in danger and, as a result, hates himself for it. Jacob, typecast by Meyer as a classic rebel, struggles to accept the violent physical changes associated with his new, shape-shifting condition. Needless to say, we as readers witness their shifting interpersonal geographies and the subsequent progressive stages of emotional growth.

${ }_{16}$ The town of Forks, where all of this occurs, not only serves as a battle site for the feuding vampires and werewolves, but also as a background for their respective prejudices. Initially, the supernatural creatures' extremely bigoted visions of each other thwart any attempts at socialization. Bella, however, becomes a major catalyst in the reconciliation of all parties concerned, especially Edward and Jacob. The reader witnesses how the contempt once felt for each other develops into mutual respect through a common cause: saving the human population of Forks. Their relationship follows a slow progression, deterred by their rivalry for Bella, but it evolves ultimately into profound respect and affection as can be seen in the final book, Breaking Dawn when Bella's life is threatened by the birth of her child. Jacob witnesses her willing sacrifice for the child's life as well as Edward's pain, and narrates his own empathetic experience when he sees the pregnant Bella. In a moment of epiphany for this character, his rage gives way to immediate understanding as he feels Edward's pain: "For a second I was just a kid-a kid who had lived all of his life in the same tiny town. Just a child. Because I knew I would have to live a lot more, suffer a lot 
more, to ever understand the searing agony in Edward's eyes" (175).

${ }_{17}$ When Jacob sees Bella dying, he empathizes with his eternal rival's grief. This is one step in the process of emotional maturation that Jacob has just taken and that

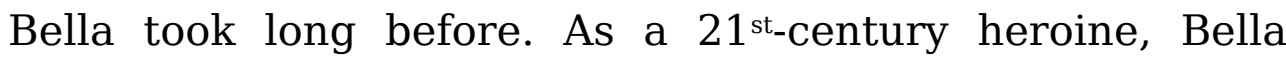
possesses incredible people skills and demonstrates an acute perception of individuals' feelings and the groups they belong to: the Cullens and the members of the Quileute tribe. Her interpersonal skills help elicit the good in people, as she manages to reconcile her divorced parents as well as the warring factions who are her friends. Early in Twilight there is a scene which best defines Bella as a character. She directly confronts Edward in their school cafeteria asking for explanations about how he had saved her life. It is a tense scene where all she asks for is honesty, but he can only insist that he is not the superhero she is imagining and that, in fact, he is very dangerous for her. To such words the heroine simply responds: "But not bad, No, I don't believe that you're bad" (94-95). Indeed, Bella's instincts about the good in all of the supernatural misfits never deceive her.

\section{Believing in the Goodwill of Family and Friends and Reader Empathy}

${ }_{18}$ Believing in people and their goodwill, as Bella does, is what Twilight is all about. The heroine's beliefs about both her vampire and shape-shifter Quileute friends are true to the end. In chapter 7 of Twilight Meyer presents Bella's rationalizing process about her feelings for Edward through a monologue that portrays her as far more mature than her newly-wed, middle-aged mom. Because Bella is typecast as a modern, rational young woman, she goes through a reasoning process about her feelings for Edward: "Only two options seemed practical. The first was to take his advice: to be smart, to avoid him as much as possible. To cancel our plans, to go back to ignoring him as far as I was able [.]" But this monologue is immediately interrupted by: "I was gripped in a sudden agony of despair as I considered that alternative. My mind rejected the pain, quickly skipping on to the next option. I could do nothing different". The monologue suddenly ends with a pronouncement convincing the wary reader as to the mysterious Edward's constant presence in Bella's life: "After all, if he was 
something... sinister, he'd done nothing to hurt me so far. In fact, I would be a dent in Tyler's fender if he hadn't acted so quickly. So quickly, I argued with myself, that it might have been sheer reflexes. But if it was a reflex to save lives, how bad could he be?" (138-139). Bella's rational nature is what eases the teen reader into believing in the good of what would otherwise be a very strange behavior coming from very strange characters.

${ }_{19}$ According to social commentator and journalist Nancy Gibbs, writing for Time magazine, belonging to a family and actually facilitating communication on a daily basis, even when not living at home, for the present, millennial generation is very important because older people's moral values are generally held to be superior to their own ("Generation Next"). This open appreciation of the older generation's experience and guidance by its young protagonists is crucial in Twilight. The three committed parent figures in this series are essential in their children's life-changing decisions but not because of their children's weakness. What Bella, Edward or Jacob all decide to do cannot be understood without their sense of commitment to family. Billy, Jacob's dad and tribe leader, helps him understand his new responsibilities as a shape-shifter. The charismatic Carlisle steers Edward on a more reflexive path, while Bella's father, Charlie, helps her recover from a severe depression after Edward has ended their relationship in New Moon.

${ }_{20}$ Family and friends become a refuge for all three protagonists throughout the saga and symbolically serve as road signs in the foggy landscapes of interpersonal geographies. The fact that the father figures in Twilight are presented as positively involved in what is happening to their children precludes a youth-culture story of the kind favored by authors of Young Adult pop fiction. Lev Grossman interprets Meyer's beliefs as a Mormon in his Time magazine article as crucial to understanding the saga's message on familial bonds. Edward and his family are not normal vampires: they are not soul-less since they are capable of renouncing human blood for moral reasons, but they need each other to provide mutual moral support (“Stephanie Meyer: A New J.K. Rowling?"). Renouncement and commitment are crucial in the lives of Meyer's heroine and heroes, as is will power that fuels it. It is also the bedrock of their families' lifestyles: in a CNN interview in November 2009, Meyer explained that her background had 
influenced in her novels which always have much more light than darkness, despite their singular subject matter.iii Belief in the goodwill of family and friends who ultimately guarantee stability and happiness is what lies at the heart of the Twilight series.

\section{Love, Happiness and Reader Emotional Neediness}

${ }_{21}$ Love, in all its dimensions, focalizes the main characters' perspectives: as an emotion, it gives meaning to everything in the supernatural world and spurs the protagonists to fight for their happiness. The pursuit of the idealized emotions of love and happiness, which Keith Oatley terms the derived emotions of cooperation, plays a crucial role in the Twilight series and is essential to understanding the reading audience's response to Meyer's work. He claims that these emotions are "fundamental" in human life, since people must learn to rely on one another (Such Stuff as Dreams 286). Patrick Hogan confirms this belief in Affective Narratology and argues that the reader actively seeks to read about the enduring emotional commitments of mutual bonding or attachment, as is the case with friendship, kinship and romantic love. In stories for a general, crosscultural audience, such as Twilight, happiness is a universal pursuit (127). Bella's relationship with Jacob after Edward had left her creates a romantic triangle in the series. It also alleviates her depression. Jacob's attraction is not so much physical as it is emotional. After spending her first afternoon with him, she reflects in New Moon: "It was Jacob himself. Jacob was simply a perpetually happy person, and he carried that happiness with him like an aura, sharing it with whoever was near him" (145).

22 Such idealization of characters, in keeping with the universal romance genre, deviates from depictive accuracy but truly augments a young reader's emotional response. It becomes very easy to overlook factors that would normally cause great concern in family and friends, such as Bella's lasting obsession with Edward or, perhaps even more disturbing, how he literally "stalks" her all over the place and at all times. These all somehow become minor details in the reading process conveniently eclipsed by an exaltation of feelings: it is teen age love at its best, just as Hogan observes in Affective Narratology when discussing how our emotional lives are tied to group identification which facilitates empathy. The simulation of another's experience 
in narrative results in this predictable, innate, identifying process which is enhanced by the emotional memory triggers that are all part of the simulation capacity in the human (Hogan 248). That it is easy to identify with Bella's circumstances in terms of feelings there is no doubt: it's not hard to feel sorry for both her and Edward, stuck in a deadend town which they consider a stop on the way to a better life. They both have to put up with silly classmates who only aggravate their feelings of frustration. Even Jake's rebellious attitude echoes an all too familiar defiance of personal circumstances. Such a scenario doubtlessly sets off the necessary emotional memory triggers in any young adult reader's mind facilitating that empathetic experience. Thus, the reader "shares" what Patrick Hogan terms "emotionally consequential experiences. These, in turn are helped along by emotion contagion which is always augmented by a categorical identification based on the reader's own individual definition of self in terms of relating to an in group-supernatural misfits or whatever (248).

${ }_{23}$ The reader's sharing of such experiences with the protagonists through an empathetic bonding process brings up the notion of "emotional neediness," which Martha Nussbaum has coined to describe how the reader, when reading a novel, is not just reading, but at the same time reading the world, and reading his or her own self. Indeed, emotions are, in effect, the reader's way of acknowledging neediness and lack of self-sufficiency. A literary work becomes an "optical instrument" (Nussbaum uses Proust's' own metaphor to explain how the reader focuses on certain personal realities), and depending on one's circumstances, one will have a corresponding range of emotions toward the characters in the story being read (22). The adolescent and young adult buyers and readers of fantasy romances react to the sense of life conveyed in the text and share it through an empathic process. Anna Silver discusses the reasons why young adult literature about adolescence and a young person's formation of identity sells so well. "During this luminal time, most adolescents prepare to leave the home and take on the increased responsibilities of adulthood.... Young Adult literature, whether realistic or fantastic, engages with these issues of identity" (123). Such an identification process is fuelled by empathy and, as Keen affirms, "empathy sells books" (105).

${ }_{24}$ Meyer's main characters have dramatic reactions, which reflects the ethos of teen age martyrdom. Indeed, apathy is 
an unknown emotional state in Twilight-except when Edward leaves at one point in the series and Bella plunges into a deep depression and becomes totally apathetic. Yet even then, family and friends bring her back from a listless state because personal involvement in Twilight is equivalent to commitment and action. An important explanation of Twilight's success as a consumer product is that its audience readily connects with the characters' extreme emotional commitment at a personal level. The role of reader identification, so necessary for "feeling with" that defines empathy, seems to work like a gap-filling mechanism by which the reader supplements given character traits with a fuller psychologically resonant portrait. Therefore the reader's judgment of the realism of the characters has an impact on his/her identification with them.iv

${ }_{25}$ Diane Sheets refers to this gap-filling, identification mechanism when she classifies Twilight as a "coming of age" novel or a Bildungsroman in a supernatural guise. Such a scenario attracts those young adult readers for whom the real world seems "too dismal, too drab, too dull, and too dead, then virtual reality as imagined in a fictional universe provides the tantalizing possibility of empowerment, free choice, and opportunity." The critic notes that Meyer's success as a writer of pop fiction is best explained by the fact that she has transposed a very conventional story with a very predictable message into a different genre-fantasy, thus making its message palpable to a secular and spiritually diverse group of readers.v

${ }_{26}$ The Cullen vampire family, for example, cherish a philosophy that makes their human willpower overcome their vampire instinct. In the new world order where good overcomes evil, the commitment to preserve human life by repressing the thirst for human blood ultimately gives meaning to their lives. Carlisle explains to Bella New Moon: "I'm hoping that there is still a point to this life, even for us. By all accounts we're damned regardless. But I hope, maybe foolishly, that we'll get some measure of credit for trying" (37). Readers of New Moon may not spiritually connect with Carlisle's comments on damnation and accounts of earthly life, but his words' appeal to human sentiment overrides any prejudices towards the vampire. This literary figure, traditionally associated with evil, is redeemed in Meyer's series. Despite their death and condemnation, human willpower makes the blood-sucking 
creatures good. Anna Silver alludes to Meyer's moralizing capacity when she discusses her exaltation of the Cullen clan (whom Bella ultimately joins) as an ideal example of constructing and imposing a world-view in teen fiction (111). The Cullens are not only depicted as physically attractive but also as personally enigmatic because of their convictions.

${ }_{27}$ This could be one of the main reasons for Meyer's vampire series' great global success in comparison with previous authors' attempts at mixing romance with the supernatural. Despite the presence of vampires and shapeshifters, Meyer's four books are basically about the tests of interpersonal commitments. Decisions affect love, and anguish, guilt, uncertainty, and various other emotional states associated with living by one's convictions, increase the reader's curiosity as to how it will all end. The implications are fundamental, according to Diane Sheets, who claims that Twilight's characters exemplify the triumph of free will and determination over today's disturbing reality, marked by the crisis of the family, the diminished bonds of love and commitment, and the loss of religious spirituality in American society.vi

${ }_{28}$ Meyer's universal romance narrative paradigm foregrounds the dilemmas of the young woman and her vampire beloved. The obstacles they encounter are predictable within the genre: they belong to identity groups that do not intermarry; they are physically separated at one point; however, there exists a force that ultimately draws them together again. The reader recognizes and perhaps identifies with the heroine's feelings as she lives her daily life, now with Edward. Bella and Edward develop strongest bonds when they talk for hours in her small room. Charlie's modest home where Bella spends her senior year of high school after her mother's new marriage acquires a new meaning: once a poor home her mother happily left, it now becomes a sacred place because of the cherished encounters with Edward. Meyer cultivates a magical atmosphere true to the romance genre in which the drab and the dull begin to convey a new emotional meaning when Bella meets her beloved, on the one hand, and performs household chores, on the other (cf. Hogan 31).

${ }_{29}$ Bella and Edward's love primarily appeals to the female reading audience, vii especially its teen segment that shows a strong emotional preference for attachment over group norms when the two are at odds. This preference is shared 
by a significant number of people, on a cross-cultural scale, and is empathic as much as egocentric. A love story such as Twilight, set in an unknown, rain-drenched, small town and featuring unlikely characters, obviously addresses adolescent readers' hopes and desires about life's possibilities. Although Bella will continue to perform the same mundane tasks at home or school, they mean more to her because love has intervened. Young female readers easily relate to this type of narrative, because, as Hogan observes, the yearning for ideals, despite the crude surrounding reality, is also part of our emotional lives (38). If, as Oatley and others claim, pop fiction provides a "buffer zone" for the reading public to experience and assimilate emotionally significant events (125), the genre deserves a serious consideration.

\section{Conclusion}

${ }_{30}$ The three characters to whom Twilight owes its popularity are the pillars of the ethos of love in human relationships. They are the attractive spokespeople for its ideology of love and happiness: Edward embodies will power, forged out of a century of self-control; Bella stands for empathy and loyalty that put an end to a war; Jacob, despite his personal struggle, represents hope and acceptance of identity. In the Time interview cited above, Meyer affirms her strong belief in human choice: "We have free will, which is a huge gift from God" (Grossman). To a great extent, the empathetic response to Twilight depends on what Anna Wierzbicka describes as shared cultural beliefs about good and bad behavior (305). It is generally accepted that good behavior is that in which one considers the common good of family, friends and society when taking actions; the emotions involved are love and happiness. Meyer expounds on such universal beliefs in her psychological thriller in which there is always a risk that vampires and werewolves can revert to wild violence. Yet, all the books have positive ends, and good behavior, rooted in love for family and friends, triumphs in Meyer's universe.

31 The Twilight series now belongs to the canon of 21 st. century young adult pop fiction. Meyer avoids explicit sex or violence, and instead weaves a thrilling supernatural tale that sheds light on very traditional relationships amongst the attractive characters. Commitment, sustained by will power and sacrifice, is the essence of Meyer's literary 
universe. If packaged differently, such an old-fashioned message may have fallen flat in terms of reader response. The involvement and believability of the supernatural misfits give a new twist to the romance narrative paradigm. ${ }_{32}$ The message of the Twilight saga is as ancient as the legendary vampire or shape-shifter, but the massive sales attest that it has been conveyed in a very attractive way. In the world that Meyer has invented. nothing comes easily, yet her characters learn to survive and ultimately to be happy. Despite their frequent confusion, the main characters have learnt about the importance of selfsacrifice and will-power in achieving common good. Meyer manipulates reader affect through empathy to lure adolescent readers into the extremely conservative world of Twilight where unreal circumstances seem familiar and desirable.

\section{BIBLIOGRAPHY}

Brakow, Gerome. The Adapted Mind. Evolutionary Psychology and the Generation of Culture. Ed. Leda

Cosmides and John Tooby. Oxford: Oxford University Press, 1992. Print.

Gibbs, Nancy "Generation Next” Time (Mar 2010)

http://content.time.magazine/article/0,9171,1971433,00.html. 10 Oct 2014. Web.

Grossman, Lev. “Stephanie Meyer: A New J.K. Rowling?” Time (April 2008)

http://content.time.magazine/article/0,9171,1734838,00.html. 10 Oct 2014. Web.

Hastings, Paul D., Carolyn Zahn-Waxler, and Keely McShane. "We Are, by Nature, Moral

Creatures: Biological Bases of Concern for Others." Handbook of Moral Development. Ed. Lin Melanie Killen and Judith G. Smetana. Mahwah, NJ: Lawrence Erlbaum Associates, 2006. 411-434. Print.

Hogan, Patrick Colm. Affective Narratology: The Emotional Structure of Stories. Lincoln: University of Nebraska Press, 2011.Print.

Hogan Patrick Colm. What Literature Teaches Us about Emotions. Cambridge University Press, 2011. Print.

Hollindale, Peter. “Ideology and the Children's Book.” Signal: Approaches to Children's Books (1988): 3-21. Print.

Kemper, Thomas D. "Social Relations and Emotions: A Structural Approach." Research Agendas in the Sociology of Emotions. Ed. T.D. Kemper. Albany, New York: State University of New York Press, 1990. 207-237. Print.

Keen, Suzanne. Empathy and the Novel. Oxford: Oxford University Press, 2010. Print. 
Kuiken, Don, et al. "Locating Self-Modifying Feelings within Literary Reading." Discourse Processes 38 (February 2004): 267-286. Print.

Kuiken, Don, et al. "Forms of Self-Implication in Literary Reading." Poetics Today 25 (Summer 2004):171- 203. Print.

Meyer, Stephenie. Twilight. New York: Little, Brown and Company, 2005. Print.

---. New Moon. New York: Little, Brown and Company, 2006. Print.

---. Eclipse. New York: Little, Brown and Company, 2007. Print.

---. Breaking Dawn. New York: Little, Brown and Company, New York, 2008. Print.

---. The Short Second Life of Bree Tanner. New York: Little Brown and Company, New York, 2010. Print.

Meyer, Stephenie. official Website. http://www/stepheniemeyer.com. 10 Oct 2014. Web.

Nussbaum Marta. Upheavals of Thought the Intelligence of Emotions. Chicago: University of Chicago Press, 2001. Print.

Oatley, Keith. Such Stuff as Dreams: The Psychology of Fiction. Chichester: Wiley-Blackwell, 2011. Print.

Oatley, Keith. , Jennifer M. Jenkins. Understanding Emotions. Oxford: Blackwell, 2006. Print. Pulver, Andrew. “The Twilight Saga: Eclipse.” The Guardian. 2 Jul 2010. 15 Oct 2014. Web http://www.theguardian.com/culture/2010/jul/02/twilight-saga-eclipse-film-review Schwartzman, Sarah. "Is Twilight Mormon?" The Twilight Mystique: Critical Essays on the Novels and Films. Ed. Amy M. Clarke and Marijane Osborn. Jefferson, North Carolina: McFarland Press, 2010. Print.

Sheets, E. Diane. “Twilight, Harry Potter, and the Youthful Reader: Morality, Gender, and \$\$s in Today's Fantasy Blockbusters.” Literary Gulagag (August 2011): 110-112.Web.

www.ideals.illiois.edu/bitstream/handle/2142/26458/literarygulag62.htmlsequence=2

Silver, Anna "Twilight is Not Good for Maidens: Gender, Sexuality, and the Family in Stephanie Meyer's Twilight Series." Studies in the Novel 42 (Spring-Summer 2010): 111-138. Print.

Toby, John and Cosmides, Leda. "The Past explains the Present: Emotional Adaptations and the Structure of Ancestral Environments.” Ethology and Sociology 11 (1990): 375-444. Print.

Wierzbicka, Anna. Emotions across Languages and Cultures: Diversity and Universals. Cambridge: Cambridge University Press, 1999. Print.

\section{NOTES}

i. This is a simplified, reader-friendly version of the concept as far as concerns this discussion of empathy but it is fully explained in Tooby and cosmides.

ii. Keene dismantles the relationship of empathy to established standards of literariness in Empathy and the Novel, maintaining that the critical habit of elimination of unworthy texts by literary critics may obscure more than it reveals about the role of human empathy in our appetite for narrative. Indeed, it may have little to do with the quality of fiction and that understanding readers' empathy almost certainly requires attending to the novels that real 
readers choose for themselves and may demand (for some critics) a discomforting de-emphasis of the so valued qualities of literariness.

iii. The complete interview which also reveals other facets to the ethos or driving force in Meyer's vampire universe can be accessed via Stephanie Meyer's official web site. CNN November, 2009; http://www.stepheniemeyer.com.

iv. The various stages of work carried out by Don Kuiken et al. lends supportive evidence to Susanne Keene's affirmations about reader empathetic response and the need to continue reading because of the need to pursue this emotion. See "Locating Self-Modifying Feelings within Literary Reading."

v. Diane Sheets provides solid evidence that pop fiction like Harry Potter and the Twilight series and their respective films are preconceived "success stories" aimed at specific markets and supported by specific interests claiming that critical reception of a book is primed by the publisher's expectation of its financial success (110-112).

vi. Diane Sheets insists in this same article that there is a pronounced gender gap in reading habits, in which girls read far more than boys which would explain this series "phenomenal success" despite "its calculated decision to forsake half the young adult audience in order to present the fevered consciousness of one hormonal young woman" (3).

\section{ABSTRACTS}

This analysis of the Twilight series focuses on the role of empathy as a communicative, crosscultural tool by which the author transmits a message that features human commitment as the key to happiness. It also raises the issue of reader emotional neediness and authorial use of empathy in popular fiction to fuel consumption of the series in order to continue "feeling with" familiar and cherished characters. The readers that have made Stephenie Meyer's Twilight series an international best-seller in the young adult/adolescent pop fiction market reflect the crucial role popular literature plays in their emotional experience. The message behind this pop fiction phenomenon is as ancient as its legendary vampire and shape-shifter characters yet its massive book sales warrant analysis of the author's role in manipulating reader affect to successfully transmit her vision of attaining happiness. The study undertaken here on the role of empathy in the Twilight series attempts to contextualize this book phenomenon within the recent work of two specialists in the area of emotions in literature: Susanne Keen and Patrick Hogan and is also inspired by the underlying current of Martha Nussbaum's work on the human ability to identify with others by means of empathy or compassion which is fomented through reading of fiction. Meyer has "tapped into the moment" in terms of what $21^{\text {st }}$ century adolescents and young adults want to read about. By looking into the Twilight series and invoking features of its on-going plot and main characters it is possible to interpret how emotions are being used by the author to transmit a specific message on human commitment and how, ultimately, it is read and "felt" by the reader. In terms of emotions theory, my analysis works on the premise that pop fiction bestsellers cannot be ignored because they accurately reflect a vast area of human emotional life. 
INDEX

Keywords: block-busters, emotional neediness, empathy as a sought-after experience and as tool for transmitting values, young adult pop fiction

\section{AUTHOR}

\section{ALICIA OTANO UNZUE}

University of Navarra 